\title{
Innovative Design on Family Exercise Equipment for Dancing Leg Stretching Based on TRIZ
}

\author{
YongMei Li, ZhongQiang Liu, LiWei Guo and Xiaoge Tian \\ Art institute, Hebei Normal University of Science and Technology, Qinhuangdao, \\ 066004, China \\ 2067377625@qq.com
}

\begin{abstract}
Based on the basic theory, instrumental effect, main methods and knowledge database on TRIZ, this paper explores the application principles, effectiveness and innovative design along with the experimental methods of TRIZ in field of family exercise equipment. And through the innovative design example of leg stretching equipment, the experimental methods are verified for its effectiveness, which provides an important reference for the application of TRIZ in exercise equipment field.
\end{abstract}

Keywords: TRIZ; dancing leg stretching equipment; experiment

\section{Introduction}

TRIZ is the abbreviation of "Theory of Inventive Problem Solving", which comes from теории решения изобретательских задач in Russian [1]. TRIZ theory was called "the Midas Touch", and it was widely used in many engineering fields and transnational corporations such as Ford, Motorola and GM, etc. Countries like Russia, Japan, US and Israel have specialized TRIZ research center where millions of great inventions are created at incredible rate. TRIZ has rigorous system of knowledge, rich theoretical contents and scientific innovative ideas, which opens a door for new product design and provides a distinguished strength for the research and development of product design. Based on the basic theory of TRIZ, and through the discussion on TRIZ's general principles used in family exercise equipment field, this paper builds up the application and framework of TRIZ theory in exercise equipment field. Moreover, through the experiments on designing, applying and developing family exercise equipment for dancing, a satisfactory design effect especially on its function, structure, appearance, and even color is accomplished, at the same time shows incomparable advantage.

\section{TRIZ}

TRIZ is a kind of systematic methodology aiming at solving human being's inventive problems on the base of knowledge and its core is theory of technology evolution [2], hereby the technology system has been evolving all the time with contradiction resolution as its driving force. The evolution speeds down following the resolution of common contradictions and mutation occurs only when the deep contradictions in the way of evolution are resolved. The TRIZ theory has 40 inventive principles and 76 standard solutions mainly including Product Evolution Theory, Technology Evolution Theory, contradiction resolving principle and substance-field analysis, etc. As a result, it offers great and unique creative solutions to product design and development [3]. 


\subsection{Main Methods and Tools}

Dr. Savransky, an internationally renowned TRIZ specialist, considers TRIZ as a human-oriented systematized methodology based on knowledge and invention problem solving theory. The main methods and tools TRIZ has are as follows:

2.1.1. Product Evolution Theory: The Product Evolution Theory in TRIZ divides the product evolution process into 4 stages: infant stage, growth stage, mature stage and retirement stage [4]. As for products in the first two stages, enterprises shall increase input to drive them into mature period so as to bring enterprises benefits at maximum; for products in mature stage, enterprises shall study the alternative technology in order to response to the future market competition; for products in retirement stage, enterprises shall eliminate them as soon as possible since profit is declining rapidly. Theory mentioned above can provide enterprises a specific and scientific support in planning for products.

At present, Technology Evolution Theory in TRIZ is expressed in several patterns: Evolution of Technique (ET) [5], Guided Technology Evolution (GTE) [6], Directed Evolution (DE) [7], and Laws of Technology Evolution [8], etc. Of all the above theories of which all have applications, DE has the most applications and grows more mature. As a branch of TRIZ Theory, DE has been developing since the mid-1980s and was named officially as Directed Evolution in 1994. The core of the Theory is the management and control of technology evolution process [9]. The Theory is that product evolution has 7 modes each of which has several evolutionary routines (see Figure 1, product evolutionary mode). The application of evolutionary modes and routines facilitates designers to work out the original and innovative product design.

\begin{tabular}{|c|c|c|c|c|c|c|}
\hline Mode 1 & Mode 2 & Mode 3 & Mode 4 & Mode 5 & Mode 6 & Mode 7 \\
\hline $\begin{array}{c}\text { Evolution } \\
\text { stage }\end{array}$ & $\begin{array}{l}\text { Increase the } \\
\text { level of } \\
\text { idealization }\end{array}$ & $\begin{array}{l}\text { Increase the } \\
\text { content of } \\
\text { resource }\end{array}$ & $\begin{array}{c}\text { Disequilibrium } \\
\text { development of } \\
\text { system } \\
\text { components }\end{array}$ & $\begin{array}{c}\text { Improve the } \\
\text { dynamics and } \\
\text { controllability } \\
\text { of system }\end{array}$ & $\begin{array}{c}\text { Simplify the } \\
\text { problem by } \\
\text { adding } \\
\text { complexity } \\
\text { of system }\end{array}$ & $\begin{array}{c}\text { Matching } \\
\text { and } \\
\text { mismatching } \\
\text { between } \\
\text { parts }\end{array}$ \\
\hline
\end{tabular}

Figure 1. Product Evolutionary Mode

Technology Evolution Theory is the core content of TRIZ. And product evolutionary modes and routines proposed in ET indicates directions and evolution status switch for product innovation, and offers an important tool for the research and improvement of product innovation design, especially that of product appearance.

2.1.2. Contradiction Resolving Principle: It's a general principle that should be observed in resolving contradictions. TRIZ mainly studies technical and physical contradictions: technical contradiction refers to the so-called compromise in traditional design, namely that the required status cannot be achieved under the influence of some part of system; physical contradiction refers to that an object has the reverse demand [10]. Under the premise of determining contradictions in accordance with standard engineering parameters, TRIZ has 39 standard contradictions and 40 principles available for designers to resolve specific contradictions. 
2.1.3. Substance-field Analysis: One of the contributions made by Altshuller to TRIZ is that substance-field description method and model for function is proposed [11-12]. According to the method, all functions can be decomposed into two kinds of substances and one field, that is to say, one function is composed of three elements. Product is the realization of function, and the product functions can be analyzed through substance-field analysis method which is one of the TRIZ tools. The model of substance-field is shown in Figure 2.

In Figure 2, S1 and S2 refer to substances, and F is field. S1 can be controlled particle, material, object or process; S2 is a tool or object used to control S1; F is energy such as mechanical energy, hydraulic energy and electromagnetic energy used to drive the interaction between S1 and S2. Fig. 2 can be interpreted to that F acts on Tool S2, and makes S2 turn S1.

According to this model, Altshuller proposed 76 standard solutions which are classified into the following 5 types [13]:

The existing system is not changed or changed a bit: 13 standard solutions;

The existing system is changed: 23 standard solutions;

System transmission: 6 standard solutions;

Inspection and measurement: 17 standard solutions;

Simplifying and improvement of strategies: 17 standard solutions.

Through the specific problems in existing system, standard solutions are turned into specific solutions, namely new concepts.

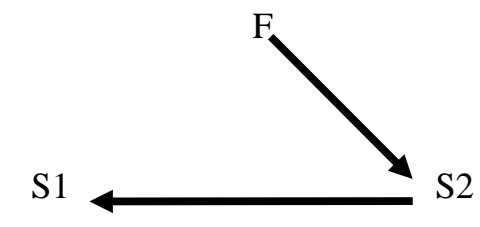

Figure 2. Su-Field Model

2.1.4. Effect: Effect refers to that problems in design are solved by the application of relevant principles in the field or other fields. For example, the innovative problems in mechanical design are solved by applying principles in fields of Mathematics, Chemistry, Biology and Electronics, etc. [14].

2.1.5. ARIZ: Algorithm for Inventive-Problem Solving: In accordance with TRIZ, the difficulty level of a problem solving depends on the description or stylized method of the problem. The clearer the problem is described, the easier the solution is found. In TRIZ, solving the inventive problems is a process of describing and stylizing the problems continually [15]. Through the process, the ultimate contradiction of initial problems will be exposed clearly and whether there is solution will also be determined. If the knowledge in hand can be used to the problem, there is solution; if not, there is no solution and natural science or technology is still in progress. The process above mentioned is achieved via ARIZ.

ARIZ, as a main tool of TRIZ, is a complete algorithm of solving inventive problem. The algorithm stylizes the initial problems step by step through adopting a set of logical process. In this algorithm, the stylization of contradiction and ideal solutions is emphasized: on one hand, the technical system is evolving towards the direction of ideal solutions; on the other hand, if a technical problem has contradiction, it will become an innovative problem.

In ARIZ, the elimination of contradictions can be supported by a powerful knowledge base of effect. The effect knowledge base consists of physical effects, chemical effects as well as geometrical effects [16]. As a principle, if there is still no solution after the analysis and effects application, the definition of initial problem will be considered wrong and the problem 
shall be defined more generally. The key of ARIZ's success lies in that the problem will be refined continually before the essence of the problem is understood until the determination of physical contradiction. This process and the resolution of physical contradiction have been supported by software.

\subsection{The TRIZ-based Problem-solving Thought and Procedure}

According to the thought of TRIZ, when solving an innovative problem, firstly, the special problem to be solved in the field shall be described in TRIZ language into a general problem in TRIZ field; secondly, the problem will be analyzed and solved by using tools of evolution theory, inventive principle, standard solution, and effect, etc., on the basis, find the general solution to the problem in TRIZ field; finally, turn the general solution into meaningful field solution according to the experience and technology of designers[17]. Model of the above thinking process is shown in Figure 3. The "specific-general-specific" method gives a full expression of a scientific and operable problem-solving thought, which provides an important theoretical basis and method for the smooth progress of innovative work.

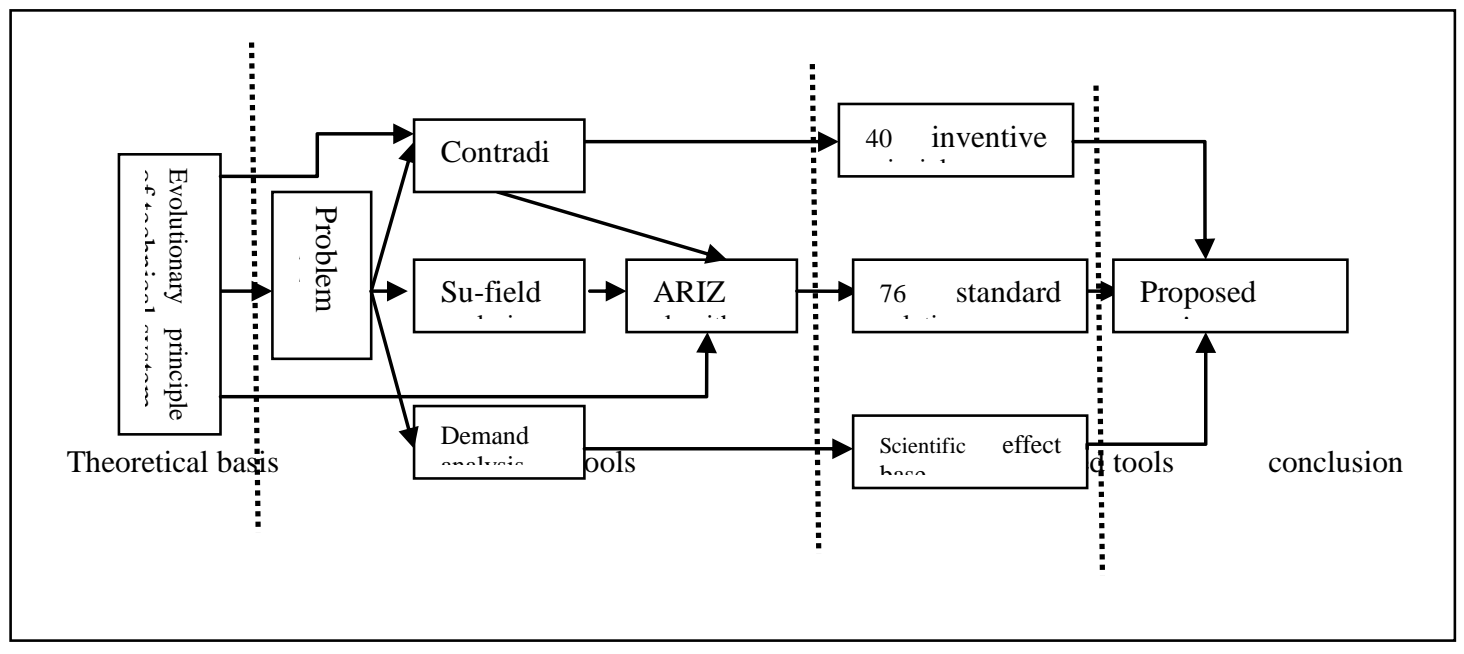

Figure 3. Architecture of TRIZ System

Researchers conclude TRIZ into 9 typical theoretical systems: 8 laws of technical system evolution, Ideal Final Result (IFR), 40 inventive principles, 39 engineering parameters and Altshuller matrix of contradictions, physical contradiction and 4 separation principles, substance-field modeling analysis, 76 standard solutions, ARIZ, scientific effects and effect knowledge base. The corresponding architecture of the above 9 systems is shown in Figure 3.

Based on the model in Figure 3 as well as the continuous supplement and improvement for it, the inventive-problem solving process model in Figure 4 is established. The model in Figure 4 is a detailed flowchart of solving problems by application of TRIZ. In this model, the search engine in TRIZ is used to turn field problems in design into TRIZ standard problems; knowledge in different levels is used to determine the general solution for standard problems; practical examples corresponding to knowledge in different levels are used for analogical thinking and to determine field solutions [18-20]. This model is also the basis of developing CAI software. 


\section{Application Analysis of TRIZ in Exercise Equipment Field}

TRIZ has brilliant adaptability and universality, and it can be widely used in fields such as mechanical design, electronic communication, and civil engineering, etc. to effectively solve the relevant difficult problems. However, in China, the relevant research on TRIZ began late; there was little research result until the late 1990s when there is only a little introduction for it. By the January, 2013, there were only 1500 papers on TRIZ in China (according to CNKI data) and most are the introduction and study on the relevant majors or specific subjects. No researchers at home in exercise equipment field has ever involve this theory, as a result, the practical examples based on TRIZ in manufacturing and designing exercise equipments are very few, even many researchers never hear of TRIZ. The same situation also occurs at abroad. Wang Youjiang wrote a practical example of TRIZ in technology evolution theory of product appearance in his master thesis in 2011 through researching on a large amount of relevant documents. This practical example is a relatively typical application in this field by now in China.

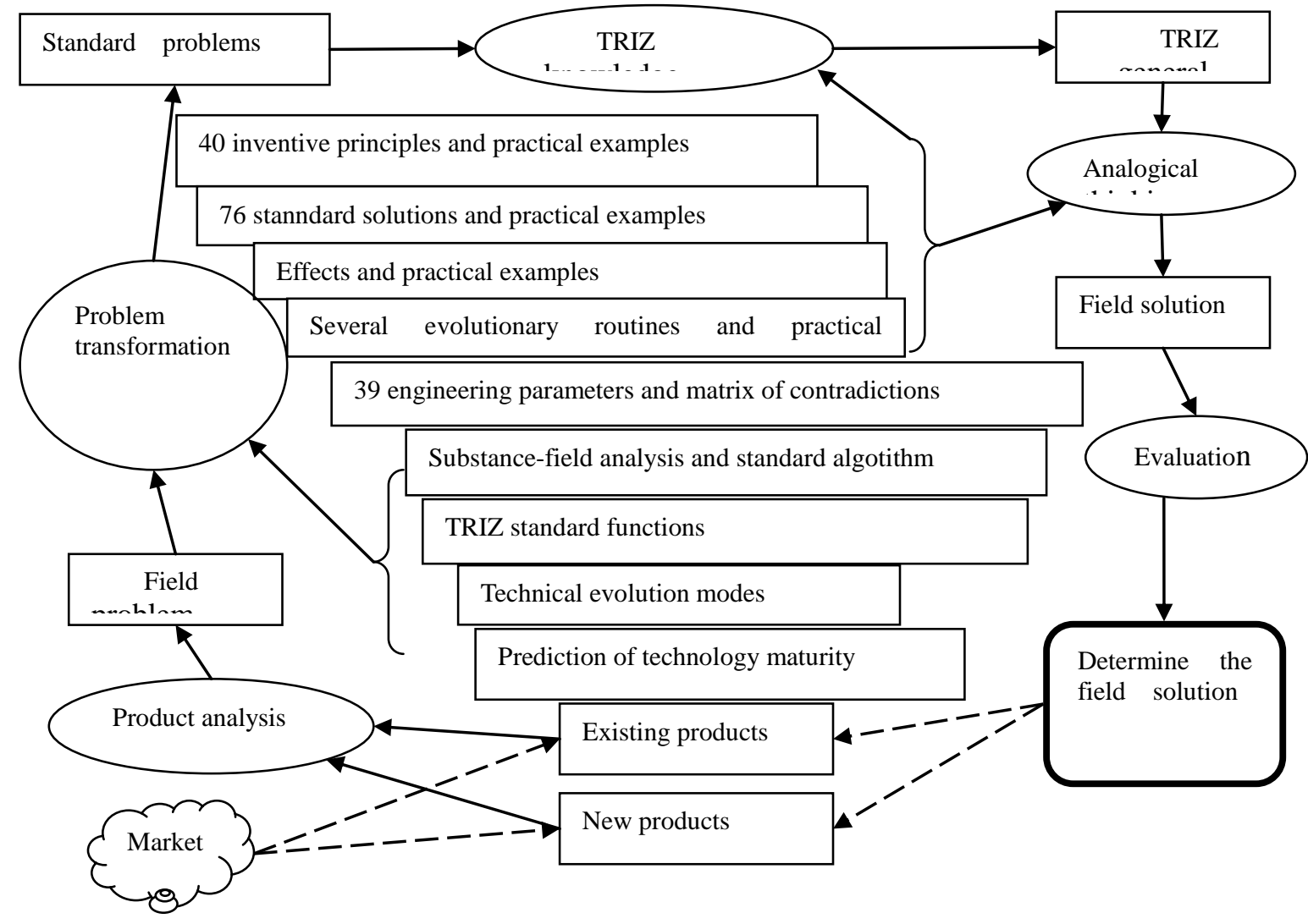

Figure 4. Inventive-problem Solving Process Model based on TRIZ 


\section{Analysis on Practical Examples: Design Verification of Leg Stretching Equipment}

\subsection{Application Analysis}

As one of important exercise equipments, leg stretching equipment belongs to a most basic device in learning dancing. Its main targets are to effectively relax and stretch leg ligaments of users, to train the softness of legs, and to exercise muscles, opening-out of crotch, full tightness of instep and extending of knees, so as to strengthen the supplement of leg muscles and to achieve the beauty of lines, intensity and looseness when the leg muscles are stretched. The leg stretching equipment is a most basic and indispensable training device.

When stretching leg muscles and ligaments, the training intensity for muscles is very hard. Every muscle is an organ consisting of muscle belly, tendon and the surrounding nerves, blood vessels and lymphatic vessels, etc., therefore, the muscles shall be stretched within scientific and safe range. And injuries resulted from over intensity, angle reversal and too hard stretching shall be avoided. At present, the ordinary leg stretching equipments are designed in single pole, see Figure 5 and 6 . Although the existing equipments simply made and widely used, accidents frequently occur because of over intensity, rotation angle reversal, too hard stretching and lack of installing controls, etc. and bring unpredictable harm to employed persons as well as fitness enthusiasts. Therefore, developing the equipment by adopting TRIZ not only has strong significance in reality, but also has very important significance in theory to develop and research products in relevant fields.

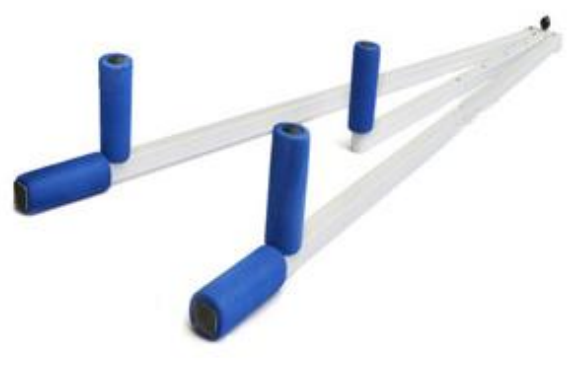

Figure 5. The Existing Leg Stretching Equipment (1)

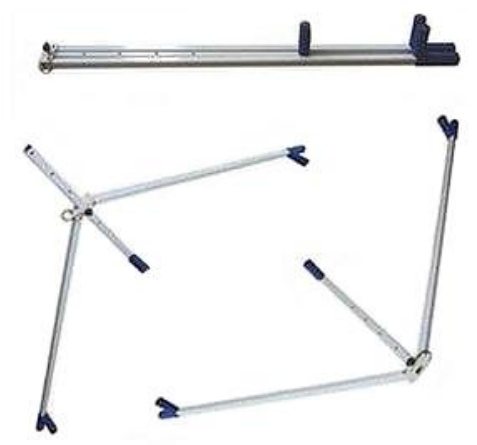

Figure 6. The Existing Leg Stretching Equipment (2)

\subsection{Determination of Technical Contradictions by the Usage of Su-field model}

Through the substance-field model of TRIZ, the functional requirements and structural features of leg stretching equipment for dancing can be effectively analyzed, which has crucial guiding effect on the prediction of new designed project. As is shown in Su-field model diagram, S1 is the leg stretching equipment for dancing; S2 is the equipment tester through mechanical, electronic and controlling devices; S1 and S2 generate interdependence via $\mathrm{F}$, and interact to each other; based on the model, the final ideal solution to the problem can be achieved. Through users' operation of the relevant devices and their effective exercises for some time, leg stretching equipment for dancing facilitates such results: on one hand, stability of leg muscles and joints as well as the elasticity of ligament are improved; on the other hand, the body parts become more elastic. 


\subsection{Technical Contradiction Analysis of Engineering Parameters under Requirements of Consumers}

According to the analysis on requirements of consumers, the consumer requirements of leg stretching equipment refer to users' objective needs on this product, including the needs of size, volume, appearance and operation, etc. Therefore, requirements of consumers (RC) facing product innovative design can be expressed as a function with all these elements as its variables:

$$
\mathrm{RC}=\mathrm{f}(\mathrm{S} 、 \mathrm{~V} 、 \mathrm{~A} 、 \mathrm{O} 、 \ldots)
$$

Based on the formulation, any change of any elements in RC may result in change of consumer requirements, thus bringing the corresponding technical contradictions. In accordance with the engineering parameters in TRIZ, problems of the existing equipments can be optimized and solved through project design, but at the same time it will result in technical contradictions under consumer requirements, which can be described as follows:

Parameters need to be improved in project:

(a) In the process of exercising muscles, relaxing legs and side opening ligaments, all the functions of the equipment need to be realized. Under the guarantee of safety (according to the general body data in Table.1), through designing a safety wheel axle to avoid reversal, adjust the scale of opening torque and separate exerciser's legs slowly in valid time to highly strengthen the flexibility of muscles and to avoid injuring muscles and deforming legs. "The length of stationary object" is described into No.4 parameter in accordance with the general engineering parameters of TRIZ.

\section{Table 1. Value of 17-21 Year-old Girls Control Parts in National Standard(Unit: cm)}

\begin{tabular}{lllllrll}
\hline & Height & $\begin{array}{l}\text { Cervical } \\
\text { height }\end{array}$ & $\begin{array}{l}\text { Waist } \\
\text { height }\end{array}$ & \multicolumn{2}{c}{$\begin{array}{l}\text { Chest } \\
\text { circumference }\end{array}$} & $\begin{array}{l}\text { Waist } \\
\text { circumference }\end{array}$ & $\begin{array}{l}\text { Hip } \\
\text { circumference }\end{array}$ \\
\hline $\begin{array}{l}\text { average } \\
\text { Standard }\end{array}$ & 162.2 & 37.8 & 100.0 & 84.8 & 67.2 & & 90.8 \\
deviation & 5.80 & 5.58 & 4.48 & 5.22 & 4.57 & 4.08 \\
Minimum & 150.0 & 123.1 & 89.0 & 75.3 & 56.2 & 78.9 \\
$\begin{array}{l}\text { Maximum } \\
\text { range }\end{array}$ & 173.2 & 150.2 & 109.8 & 100.6 & 84.3 & 104.0 \\
\hline
\end{tabular}

(b) It is presented from the survey data of users that when using the equipment, the required floor space for trainee is small. Generally, the space of modern family is relatively small, so the occupied area when exercising stretching legs should not be too large, and it's enough to only spread the equipment apart. Therefore, "the volume of stationary object" (the system volume in use in prescribed way) is described into No.6 parameter in accordance with the general engineering parameters of TRIZ.

(c) Family exercise equipment belongs to sport equipment, so it has high requirements for performance. However, as exercise equipment, it also has high requirements for appearance and form in the process of usage. As a result, the requirements for product form such as appearance, structure and color, etc. must adapt to the aesthetic needs of family, in order to bring users a delighted and relaxed mental mood. Therefore, "form" (the appearance, style and state shown by the system) is described into No.12 parameter in accordance with the general engineering parameters of TRIZ.

(d) Apart from the safe usage of equipment, users also have important participation on simple, convenient and effective operation of it. So not only users should keep a correct posture and way of exerting strength, but also the leg stretching equipment should be 
designed with comfortable operation and higher error-tolerant rate so as to meet consumers' needs. "Operability" (simple, effective, flexible and comfortable operation) is described into No.33 parameter in accordance with the general engineering parameters of TRIZ.

Meanwhile, parameters that may cause deterioration are as follows:

(a) No.2 parameter "weight of stationary object", namely the quality of equipment or object itself;(b) No.10 parameter "force", namely any power that may cause changes of velocity, direction or shape to free objects;(c) No.11 parameter "stress or pressure", namely the internal force generating interactions among all parts of the object to fight against the effect of external factors and to recover the object's position when the object is deformed because of external reasons (such as the change of stress, humidity and temperature);(d) No.13 parameter "stability of structure", namely the structure's ability of maintaining its original equilibrium state under the effect of load.

\subsection{Construction of Technical Matrix of Contradictions}

After determining the description of engineering parameters, the appropriate principles of invention should be located through matrix of contradictions. As is shown in Table 2, the inventive principles in serial numbers have been achieved.

Table 2. Matrix of Contradictions

\begin{tabular}{lccccc}
\hline \multirow{2}{*}{$\begin{array}{l}\text { Parameters causing } \\
\text { deterioration }\end{array}$} & $\begin{array}{c}\text { 4 length of } \\
\text { object }\end{array}$ & 6 volume of object & 12 form & 33 operability \\
\hline 2 weight & $10,1,29,35$ & $35,30,13,2$ & $35,4,15$, & $6,13,1,32$ \\
10 force & 28,1 & $1,8,36,37$ & $10,35,40$, & $1,28,3,25$ \\
11 pressure & $1,14,35$ & $10,15,36,37$ & $35,4,15$, & 11 \\
13 stability & 37 & 39 & $22,1,18,4$ & $32,35,24$, \\
\hline
\end{tabular}

\subsection{Improvement of Design Project in Accordance with TRIZ Inventive principles}

The inventive principles achieved in matrix of contradictions have important significance of guidance and universality, but for the specific project and design, practical analysis according to features the product itself has is still needed so as to achieve the specific solution to the specific problem. Through the author's careful analysis and filtering, the proper project of improving the product design is found from the above inventive principles, which can be described as follows:

(a) According to No.11 inventive principle "compensate object's relatively low reliability by adopting the pre-prepared emergency measures" and No.8 inventive principle "weight compensation", the installation of bearing safety device can overcome the shortcomings that exist in the existing leg stretching equipments: in lacking of bearing safety device, strains often occur because of leg reversal when the range of motion is increased. What's more, this device can greatly decrease the viscosity of leg muscles and increase the speed of muscle contradiction and relaxation so as to avoid the strains of muscle.

(b) According to No.14 inventive principle "surface curving, namely replacing the straight lines and plane with curved lines or sphere and turning parallelepiped or cube structure into spherical structure" and No.11 inventive principle "flexible shell and thin film, namely replacing standard structure with flexible shell and thin film", the existing leg equipments' simple line structure and rigid metal shell are changed by parceling flexible materials outside the equipments, that is in particular add cushions to the equipment in order to meet the need for comfort of long-time lying and sitting. Adding the back cushion and the leg placing 
device of curved surface can greatly relieve the backache and induction force of lower limb muscles caused by the increasing of stress and pressure in stretching legs, and can protect the $45^{\circ}$ opening-out of power leg so as to relieve the down pressure from the hip joints, and to avoid the occurrence of lateral bending of buttock and vertebral.

(c) According to No.1 inventive principle "separation, namely separating an object into an independent group through collapsing and disassembling", design the main structure and devices of leg stretching equipment in modular manner. For example, designing the back cushion, side cushion for legs and separating device in detachable or assembled way can not only reduce the floor space in usage and bring the effect of convenience, but also can save space when putting it away or storing it and be operated handily.

(d) According to No.32 inventive principle "color changing, namely changing the color of objects or environment", No.35 inventive principle "changing of physical or chemical parameters, namely changing the physical state and increasing foam materials" and No.14 inventive principle "surface curving", change the appearance and form of the equipment. The adopting of color spray, chamfering, surface curving and streamlining designing style not only can bring people visual aesthetic experience, but also can effectively decrease the potential risks in usage, which accords with the human-oriented design concept in modern design.

(e) According to No.40 inventive principle "composite materials, namely replacing homogeneous materials with composite materials", and No.24 inventive principle "by virtue of mediator, namely realizing the required motion by using mediator", under the need of strengthening stability, lighten the whole quality of the leg equipment and increase the opening device of rotation compass so as to change the old way of realizing split and increasing muscle extensibility. The designed rotation compass is safe and effective. Besides, it can gradually increase flexibility of legs in lightly loaded and highly frequent exercises; can reduce the viscosity of muscles; can alleviate the strength loss of exercisers; can improve the coordination ability of all muscles; and can increase the toughness of tendon and joints.

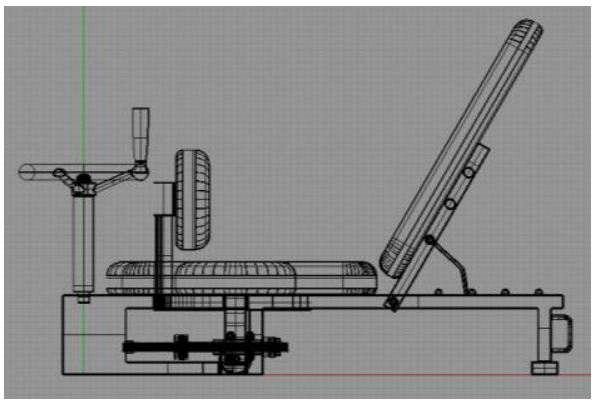

(a)

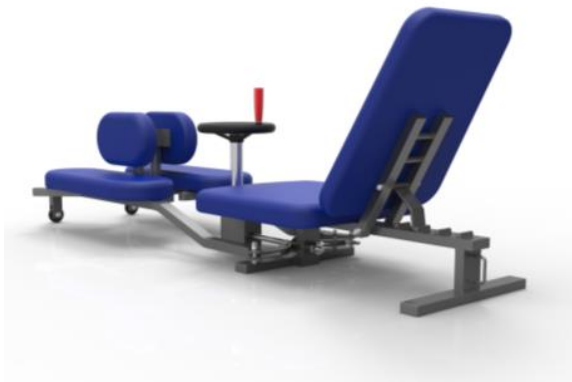

(c)

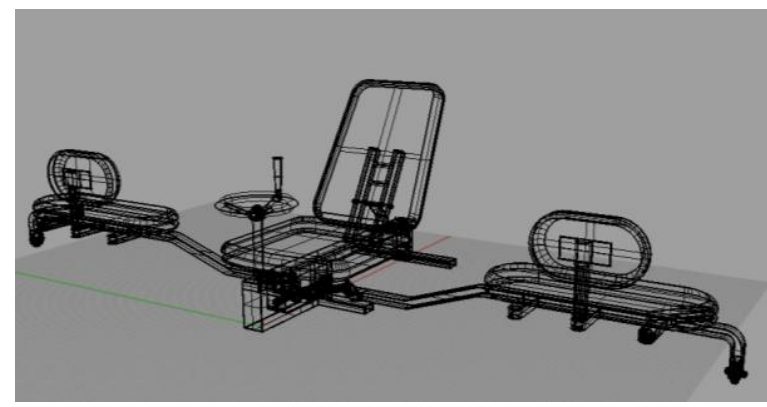

(b)

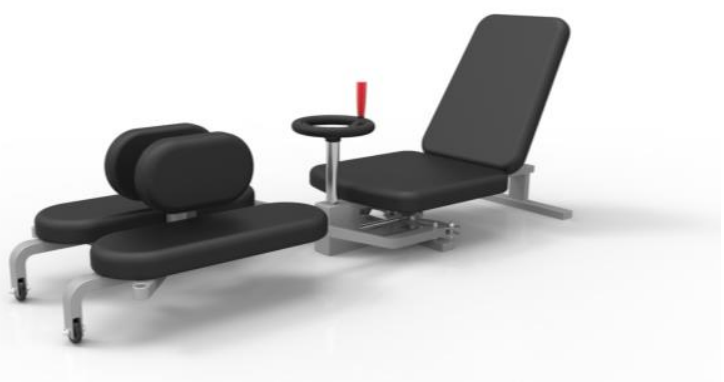

(d)

Figure 7. a, b, c, d-Project Design of Leg Stretching Equipment for Dancing 


\section{Conclusion}

By integrating the design elements that have been improved by TRIZ inventive principles, the project of family leg stretching equipments for dancing is designed, as is shown in Figure 7. Through the testing and evaluation of catia and Rhino software, it shows that the equipment not only improves the shortcoming of the existing products, but also promotes the relevant needs of users. The project achieves such features of basic functions as safe usage, small floor space, convenient storage, good divisibility in appearance, jumpiness and vividness in feeling; opening device of compass facilitates operation and observation; cushion, back cushion and side cushion for legs are comfortable, and the structure of cushions can effectively prevent from operators' striking pressure so as to relieve the muscle injuries of buttock, waist and legs; the installing structure in modular manner is user-friendly. The experimental results show that the improved design project of exercise equipment based on TRIZ is feasible. The specific process of the project is as follows: on the basis on functional analysis, the inventive methods of setting out contradiction matrix are searched to achieve the technical effects between the overall function and sub-functions and to filter the variable design elements; concerning of the existing problems, make innovations, improvements and designs by applying various creative techniques; find variants to variable elements as many as possible by adopting principle of matrix and build a morphological matrix table; combine the variants and get a required innovative project of exercise equipment that adapts to the practical needs.

\section{References}

[1] S. Riann, "Systematic innovation and the. -underlying principles behind TRIZ and TOC", Joumal of Materials Processing Technology, vol. 139, no. 8, (2003), pp. 120-126.

[2] X. Mao, X. Zhang and S. M. Abourizk, "Enhancing value engineering process by incorporating inventive problem-solving techniques", Journal of Construction Engineering and Management, vol. 135, no. 5, (2009), pp. 416-424.

[3] Q. Zheng and Z. Tang, "The Structural Improvement Design for Gear Pump Based on TRIZ", 2010 3rdInternational Conference on Computer and Electrical Engineering, (2010), p. 11.

[4] R H Sturges, K. O'shaughnessy and M J Kilani, "Computational model for conceptual design based on extended function logic", Artificial Intelligence in Engineering Design, Analysis and Manufacturing, vol. 10, no. 4, (1996), pp. 255-274.

[5] L M. Darrell, "Better technology forecasting using systematic innovation methods", Technology Foresting \& Social Change, vol. 70, (2003), pp. 779-795.

[6] Q.-f. Wei, C. Zhao and X. Gu, "Innovative Design in Biomedical Engineering Medical Instrumentation Based On TRIZ”, Journal of Engineering Design, vol. 18, no. 5, (2011), October, pp. 32-326.

[7] R. Srinivasan and A. Kraslawski, "Application of the TRIZ creativity enhancement approach to designinherently safer chemical processes”, Chemical Engineering and Processing, vol. 4, no. 5, (2006), pp. 507-514.

[8] D. Savransky, "TRIZ: the methodology of inventive problem-solving", Industrial Physicist, vol. 2, no. 4, (1996), p. 22.

[9] X. Zhang, X. Mao and S M Abourizk, "Developing a knowledge management system for improved value engineering practices in the construction industry", Automation in Construction, vol. 18, no. 6, (2009), pp. 777-789.

[10] F. Y. Zhang, H. C. Zhang and H. Zheng, "Energy-saving product innovative design process based on TRIZ/AD”, Proceedings - (2010) IEEE 17th International Conference on Industrial Engineering and Engineering Management, IE and EM2010[Z],Xiamen, China: 2010325-328.

[11] Y. Zhenhe and L. Xin, "Model Evaluation Based on Emotional Furniture Industrial Design Elements", International Journal of Advancements in Computing Technology, vol. 22, no. 4, (2012), pp. 73-78.

[12] Z. Zheng and J. Zhang, "Model for Evaluating the Industrial Design with Interval Grey Linguistic Variables", International Journal of Digital Content Technology and its Applications, Advanced Institute of Convergence Information Technology, vol. 6, no. 15, (2012), pp. $136 \sim 142$, 
[13] C. Liu, "Using VBA to design curved surface based on CATIA software", Journal of Guizhou University: NaturalScience, vol. 24, no. 5, (2007), pp. 495.

[14] Z. Ye and Q. Bai, "Agricultural Implementation Security Research Based on Ergonomics", Journal of Convergence Information Technology, vol. 20, no. 7, (2012), pp. 65-71.

[15] Z. Ayag, "An integrated approach to evaluating conceptual design alternatives in a new development environment”, International Journal of Production Research, (2005), vol. 43, no. 4, pp. 687-713.

[16] H. T. and L J. Chen, "The conflict-problem-solving CAD software integrating TRIZ intoeco-innovation", Advances in Engineering Software, vol. 35, no. 8, (2004), pp. 553-556.

[17] J. H. Lee, "Stimulating designers' creativity based on a creative evolutionary system and collective intelligence in product design", International Journal of Industrial Ergonomics, vol. 40, no. 3, (2010), pp. 295-305

[18] B. Sencer, Y. Altintas and E. Croft, "Feed optimization for five-axis CNC machine tools with drive constraints", International Journal of Machine Tools and Manufacture, (2008), June.

[19] B. Verworn, "How German measurement and control firms integrate market and technological knowledge into the front endof new product development", International Journal of Technology Management, vol. 34, nos. 3-4, (2006), pp. 379-389

[20] H. A. Haghiac, "Quality function deployment as a tool for including customer preferences in optimizing vehicle dynamic behavior", International Journal of Vehicle Design, vol. 39, no. 4, (2005), pp. 311-330.

\section{Authors}

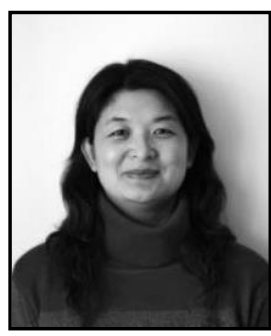

Yongmei Li, She is a graduate school student of Hebei Normal University. Now she is also a worker at Art Institute, Hebei Normal University of Science and Technology too. Her research focus is Dance performance and Dance Teaching.

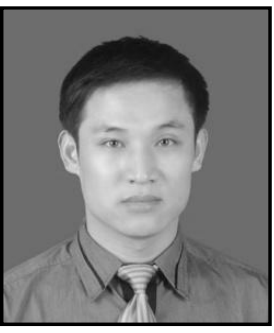

Zhongqiang Liu, $\mathrm{He}$ is a graduate school student of Hebei University. Now he is also a worker at Art Institute, Hebei Normal University of Science and Technology too. His research focus is vocal music teaching.

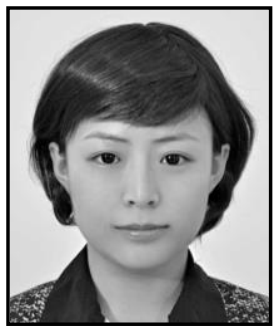

Liwei Gou, She is a graduate school student of Northeast Normal University. Now she is also a worker at Art Institute, Hebei Normal University of Science and Technology too. Her research focuses is Musicology.

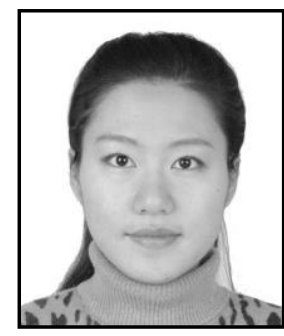

Xiaoge Tian, She is a graduate school student of Shanghai conservatory of music. Now she is also a worker at Art Institute, Hebei Normal University of Science and Technology too. Her research focus is Ethnomusicology 
International Journal of Signal Processing, Image Processing and Pattern Recognition Vol.8, No.3 (2015) 